ADVANCE RESEARCH JOURNAL OF SOCIAL SCIENCE
$\begin{gathered}\text { ReSEARCH } \\ \text { ArTICLE }\end{gathered}$ $\begin{array}{cc}\text { volume } 7 \text { | Issue 2 | December, 2016 | 263-266 } \\ \text { e ISSN-2231-6418 }\end{array}$

\title{
Environmental ethics among adolescents: A study of gender and locale difference
}

Manpreet Kaur*, Tejpreet Kaur Kang and Seema Sharma Department of Human Development, College of Home Science, Punjab Agricultural University, LUDHIANA (PUNJAB) INDIA (Email: rcumesh@ rediffmail.com)

\section{ARTICLE INFO :}

Received

Revised

15.10 .2016

Accepted

10.11 .2016

KEY WORDS :

Environmental ethics, Locale, Gender

HOW TO CITE THIS ARTICLE :

Kaur, Manpreet, Kang, Tejpreet Kaur and Sharma, Seema (2016). Environmental ethics among adolescents: A study of gender and locale difference. Adv. Res. $J$. Soc. Sci., 7 (2) : 263-266, DOI: 10.15740/ HAS/ARJSS/7.2/263-266.

*Author for correspondence

\begin{abstract}
The present study entitled 'environmental ethics among rural and urban adolescent boys and girls' was undertaken in the Kapurthala district of Punjab. The study was designed to compare environmental ethics of adolescents across gender and locale. The sample comprised of 200 adolescents (100 boys and 100 girls) of age group 14-16 years. Environmental Ethics Scale by Taj was used to assess the environmental ethics of the adolescents. Gender differences revealed that girls possessed more environmental ethics as compared to boys. In locale differences urban adolescents were found to be more environment sensitive as compared to rural adolescents.
\end{abstract}

